\title{
Piperine potentiates the hypocholesterolemic effect of curcumin in rats fed on a high fat diet
}

\author{
YAOSHENG TU, DONGMEI SUN, XIAOHUI ZENG, NAN YAO, \\ XUEJUN HUANG, DANE HUANG and YUXING CHEN \\ Traditional Chinese Medicine Pharmacological Research Office, Guangdong Provincial Institute
of Traditional Chinese Medicine, Guangzhou, Guangdong 510095, P.R. China
}

Received November 30, 2013; Accepted March 7, 2014

DOI: $10.3892 /$ etm.2014.1717

\begin{abstract}
It has previously been demonstrated that curcumin possesses a hypocholesterolemic effect and potentiates numerous pharmacological effects of curcumin, however, the mechanisms underlying this hypocholesterolemic effect and the interaction between curcumin and piperine remain to be elucidated. In the present study, male Sprague-Dawley rats were fed on a high-fat diet (HFD) to establish a hyperlipidemia (HLP) model. Co-administration of curcumin plus piperine was found to decrease the levels of total cholesterol (TC), triglyceride (TG) and low-density lipoprotein cholesterol in the serum and liver, as well as increase the levels of fecal TC, TG and total bile acid, compared with administration of curcumin alone. Curcumin plus piperine also markedly increased the levels of high-density lipoprotein cholesterol. Furthermore, compared with administration of curcumin alone, administration of curcumin plus piperine resulted in a significant upregulation of the activity and gene expression of apolipoprotein AI (ApoAI), lecithin cholesterol acyltransferase (LCAT), cholesterol 7 $\alpha$-hydroxylase (CYP7A1) and low-density lipoprotein receptor (LDLR). In conclusion, these results indicated that co-administration of curcumin plus piperine potentiates the hypocholesterolemic effects of curcumin by increasing the activity and gene expression of ApoAI, CYP7A1, LCAT and LDLR, providing a promising combination for the treatment of HLP.
\end{abstract}

\section{Introduction}

Cardiovascular disease (CVD) is one of the major causes of mortality worldwide. An increase in blood total cholesterol (TC) levels, which is regulated by cholesterol absorption, synthesis, storage and excretion, is one of the major risk factors

Correspondence to: Professor Yaosheng Tu, Guangdong Provincial Institute of Traditional Chinese Medicine, $60 \mathrm{Hengfu}$ Road, Guangzhou, Guangdong 510095, P.R. China

E-mail: tcmgdp@163.com

Key words: curcumin, piperine, cholesterol, rat, mRNA leading to the development of CVD (1). At present, the levels of TC in the serum under hyperlipidemic conditions may be lowered by diet or medication.

Curcumin, a hydrophobic polyphenol derived from the rhizome of the herb Curcuma longa, has been widely used as a spice and a coloring agent, and is a major ingredient of curry powder (2). However, several studies have demonstrated that curcumin also possesses anti-oxidant, anti-tumor and anti-inflammatory properties (3-11). In addition, previous studies on animals and humans have demonstrated that curcumin is capable of decreasing the levels of TC in the blood (12-16). However, curcumin has not yet been approved as a therapeutic agent for hyperlipidemia (HLP), mainly due to problems with its bioavailability (17).

Piperine is responsible for the pungency of spices gained from Piper nigrum and Piper longum (sources of black or long pepper) (18). Piperine is capable of affecting the metabolism of other substances, and if consumed with curcumin, it significantly increases the bioavailability of curcumin by inhibiting hepatic and intestinal glucuronidation $(17,19,20)$. For example, piperine as an adjuvant increases the efficacy of curcumin by mitigating benzo(a)pyrene toxicity and enhancing the protective effect of curcumin against chronic unpredictable stress-induced cognitive impairment and depressive disorders (21-23).

A previous study investigated the effect of curcumin, piperine and quercetin in high-fat diet (HFD) and low-dose streptozotocin-induced diabetic rats; however, the study focused on glucose intolerance and oxidative stress (24). Therefore, whether piperine is able to affect the hypocholesterolemic effects of curcumin remains to be elucidated. The aim of the present study was to investigate the hypocholesterolemic effect of curcumin plus piperine on cholesterol metabolism in rats fed on a HFD.

\section{Materials and methods}

Materials. Curcumin and piperine were purchased from Sigma-Aldrich (St. Louis, MO, USA). TC, triglyceride (TG), high-density lipoprotein cholesterol (HDL-C), low-density lipoprotein cholesterol (LDL-C) and total bile acid (TBA) kits were purchased from Nanjing Jiancheng Bioengineering Institute (Nanjing, Jiangsu, China). The free cholesterol (FC) kit was purchased from Applygen Technologies Inc. 
(Beijing, China). Apolipoprotein AI (ApoAI) and ApoB kits were purchased from Shanghai Rongsheng Biotech Co., Ltd. (Shanghai, China). The bicinchoninic acid assay kit was obtained from Tiangen Biotech Co., Ltd. (Beijing, China). Ethanol and isopropanol of analytical grade were purchased from Dikma Technologies, Inc. (Beijing, China). TRIzol ${ }^{\circledR}$ reagent was purchased from Invitrogen Life Technologies (Carlsbad, CA, USA). The RevertAid ${ }^{\mathrm{TM}}$ First Strand cDNA Synthesis kit and the Maxima ${ }^{\mathrm{TM}}$ SYBR-Green/Fluorescein qPCR Master mix (2X) were purchased from Thermo Fisher Scientific (Burlington, ON, Canada).

Animals, diets and treatments. Thirty male Sprague-Dawley (SD) rats weighing between 180 and $220 \mathrm{~g}$ were purchased from the Guangdong Medical Laboratory Animal Center (Guangzhou, Guangdong, China). All rats were kept in a specific pathogen-free room under controlled conditions. A $12 \mathrm{~h}$ light-dark cycle was maintained, with lights on between 6:00 a.m. and 6:00 p.m., and the temperature was maintained at $23 \pm 1^{\circ} \mathrm{C}$. The rats were provided with the standard laboratory diet and tap water and allowed to acclimatize to the environment for 1 week prior to the start of the experiment. Following 1 week, the rats were randomly divided into five groups with six rats in each group. The rats in the normal control $(\mathrm{N})$ group were fed on a normal diet, whilst rats in the other groups were fed on a HFD, which contained $10 \%$ fat and $2 \%$ cholesterol for 8 weeks, in order to induce hypercholesterolemia. Following 5 weeks, with the exception of rats in the $\mathrm{N}$ group and the HFD control $(\mathrm{H})$ group, rats were administered curcumin (100 mg/kg/day; C group), piperine ( $5 \mathrm{mg} / \mathrm{kg} / \mathrm{day}$; P group) or curcumin $(100 \mathrm{mg} / \mathrm{kg} /$ day) plus piperine $(5 \mathrm{mg} / \mathrm{kg} /$ day; $\mathrm{CP}$ group), dissolved in corn oil for 4 weeks. Rats in the $\mathrm{N}$ and $\mathrm{H}$ groups were orally administered corn oil for 4 weeks. At the end of 8 weeks all the rats were sacrificed in a $100 \%$ ether atmosphere and the blood, liver and feces were collected.

All experimental protocols were approved by the Animal Ethics Committee of Guangdong Provincial Institute of Traditional Chinese Medicine (Guangzhou, Guangdong, China). The care and treatment of the animals were conducted in accordance with the guidelines (publication no. 85-23, revised 1996) provided by the National Institutes of Health (Betheseda, MA, USA) and the U.S. Department of Agriculture (Washington, DC, USA).

Serum sampling. Blood was collected from the abdominal aorta and left at room temperature for coagulation. The serum samples were obtained by centrifugation at $3,300 \times \mathrm{g}, 4^{\circ} \mathrm{C}$ for $10 \mathrm{~min}$ and stored at $4^{\circ} \mathrm{C}$ for further analysis.

Liver sampling. Liver samples $(0.3 \mathrm{~g})$ from each rat were immediately removed and homogenized in phosphate-buffered saline (PBS; pH 7.2; $0.15 \mathrm{~g} / \mathrm{ml}$ ) at $4^{\circ} \mathrm{C}$. The supernatant was centrifuged at $3,300 \times \mathrm{g}$ at $4^{\circ} \mathrm{C}$ for $10 \mathrm{~min}$ and stored at $-80^{\circ} \mathrm{C}$ for analysis of the hepatic lipid levels. In addition, $0.1 \mathrm{~g}$ liver samples from each rat were immediately removed, washed with PBS, dried on filter paper and stored at $-80^{\circ} \mathrm{C}$ for further analysis using polymerase chain reaction (PCR).

Feces sampling. Feces from each rat were collected following 8 weeks for 3 days and dried at $60^{\circ} \mathrm{C}$. Feces were then weighed and ground into a powder. A total of $0.5 \mathrm{~g}$ of feces powder from each rat was extracted three times with $10 \mathrm{ml} \mathrm{95 \%}$ ethanol at $60^{\circ} \mathrm{C}$ and then filtered as well as extracted three times with $10 \mathrm{ml} 95 \%$ ethanol at $60^{\circ} \mathrm{C}$ and then filtered. The residue was dissolved in PBS by sonication. The final solution was adjusted to a suitable concentration and frozen at $-80^{\circ} \mathrm{C}$ for further analysis.

Measurement of lipid levels in the serum, liver and feces. The serum, liver and fecal levels of TC, TG, HDL-C, LDL-C, ApoAI and ApoB were determined using the respective assay kits in accordance with the manufacturer's instructions. All samples were detected using the 722 Grating Spectrometer (Shanghai Cany Precision Instrument, Co., Ltd., Shanghai, China).

Measurement of TBA levels in feces. The TBA level in the feces extract was analyzed as previously described by Feldmann et al (25) using an assay kit in accordance with the manufacturer's instructions. All samples were detected using the 722 Grating Spectrometer (Shanghai Cany Precision Instrument, Co., Ltd.).

Measurement of lecithin cholesterol acyltransferase (LCAT) activity in serum. For the serum LCAT activity, the auto-matrix method was used to transfer $15 \mu \mathrm{l}$ of serum into tubes A and B. Tube A was placed in an ice bath and tube B was placed at $37^{\circ} \mathrm{C}$. The FC level in the two tubes was measured $60 \mathrm{~min}$ after using an assay kit in accordance with the manufacturer's instructions. The LCAT activity was then calculated according to the decrement in non-esterified cholesterol by comparing the FC content in each tube. The LCAT activity was then determined using the previously described formula (26). All samples were detected using the 722 Grating Spectrometer (Shanghai Cany Precision Instrument, Co., Ltd.).

Measurement of cholesterol $7 \alpha$-hydroxylase (CYP7A1) activity in the liver. The rat liver microsomes were prepared as previously described (27-29). CYP7A1 activity in the rat liver was determined using high-performance liquid chromatography quantification of cholesterol metabolites, as described by Hylemon et al (30).

Quantitative PCR ( $q P C R)$ analysis of hepatic mRNA levels. Total RNA was extracted from the rat liver samples using TRIzol reagent in accordance with the manufacturer's instructions. A total of $3 \mu \mathrm{g}$ of total RNA was reverse transcribed into cDNA using the First Strand cDNA Synthesis kit at $42^{\circ} \mathrm{C}$ for 1 h. qPCR was performed using the $\mathrm{iQ}^{\mathrm{TM}}$ real-time PCR detection system (Bio-Rad, Hercules, CA, USA) and performed in a reaction mix containing $1 \mu \mathrm{l}$ cDNA, $12.5 \mu \mathrm{l} \mathrm{Maxima}^{\mathrm{TM}}$ SYBR-Green/Fluorescein qPCR Master mix (2X), $1 \mu \mathrm{M}$ forward primer and $1 \mu \mathrm{M}$ reverse primer in a total volume of $25 \mu \mathrm{l}$. The cDNA was amplified using specific primers under the following conditions for 45 cycles: $94^{\circ} \mathrm{C}$ for $30 \mathrm{sec}$, an annealing temperature of $55^{\circ} \mathrm{C}$ for $30 \mathrm{sec}$ and then $72^{\circ} \mathrm{C}$ for $50 \mathrm{sec}$, with a final incubation at $72^{\circ} \mathrm{C}$ for $7 \mathrm{~min}$. The PCR primers used were as follows: ATP-binding cassette transporter A1 (ABCA1; GenBank accession no. NM_178095; $145 \mathrm{bp}$ ) forward, 5'-CAGCAACTACAGTGGCGGTAACA-3' 
and reverse 5'-AATGCTTAGGGCACAATTCCACA-3'; ApoAI (GenBank accession no. NM_012738; 149 bp) forward, 5'-A AGGCATCTAAAGGTTGT-3' and reverse 5'-TCAGGGTAGGGTGGTT-3'; CYP7A1 (GenBank accession no. NM_012942; 291 bp) forward, 5'-TGCCGTGTT GGTGAG-3' and reverse 5'-TTCGCAGAAGTAGTGTAAT-3'; HMG-CoA reductase (HMGCR; GenBank accession no.NM_013134;249bp) forward,5'-TGACGCTCTGGTGGA-3' and reverse 5'-GTTACTGGGTTTGGTTTAT-3'; LCAT (GenBank accession no. NM_017024; 163 bp) forward, 5'-GCTACCGAAAGACAGAGG-3' and reverse 5'-CCAAAG CCAGGGACA-3'; low-density lipoprotein receptor (LDLR; GenBank accession no. NM_175762; 117 bp) forward, 5'-CAG ACCCAGAGCCATCGTAGTG-3' and reverse 5'-GTCACC AGAGAGTAGATGTCTAC-3'; scavenger receptor B1 (SR-B1; GenBank accession no. NM_031541; 141 bp) forward, 5'-TAC TTGTCCGTCTACT-3' and reverse 5'-CGTGTCATT GTCATTG-3'; 18S (GenBank accession no. M11188; 205 bp) forward, 5'-TTCAGCCACCCGAGAT-3' and reverse 5'-GCT TATGACCCGCACTTA-3'. The products were analyzed using the $\mathrm{CT}$ value and all values were normalized against the $18 \mathrm{~S}$ mRNA level. The final result was calculated using the $2^{-\Delta \Delta \mathrm{Ct}}$ method.

Statistical analysis. All the data are presented as the mean \pm standard deviation $(n=6)$. Statistical analysis was performed using the SPSS version 17.0 statistical software (SPSS, Inc., Chicago, IL, USA). A one-way analysis of variance was used to analyze differences between the biochemical parameters among the groups, followed by Dunnett's significant post-hoc test for pairwise multiple comparisons. $\mathrm{P}<0.05$ was considered to indicate a statistically significant difference.

\section{Results}

Effects of $C, P$ and $C P$ administration on the growth parameters of rats fed on a HFD. As shown in Table I, no significant difference between the initial body weight, final body weight, body weight gain, food intake and relative liver weight among the groups was identified.

Effects of $C, P$ and $C P$ administration on the serum lipid levels of rats fed on a HFD. Table II shows the serum levels of TC, TG, HDL-C and LDL-C from rats in each group. TC, TG, HDL-C and LDL-C levels in the $\mathrm{H}$ group were significantly different compared with the $\mathrm{N}$ group. The levels of TC, TG and LDL-C in the $\mathrm{H}+\mathrm{C}$ and $\mathrm{H}+\mathrm{CP}$ groups were markedly lower compared with those in the $\mathrm{H}$ group, whilst the level of HDL-C in the $\mathrm{H}+\mathrm{CP}$ group was markedly elevated compared with the $\mathrm{H}$ group. In addition, compared with the $\mathrm{N}$ group, the levels of ApoAI and ApoB were significantly different in the $\mathrm{H}$ group. Administration of $\mathrm{CP}$ significantly increased the levels of ApoAI.

Effects of $C, P$ and $C P$ administration on the hepatic and fecal lipid levels of rats fed on a HFD. The hepatic TC and TG levels were significantly increased in the $\mathrm{H}$ group compared with the $\mathrm{N}$ group, whilst the hepatic TC and TG levels in the $\mathrm{H}+\mathrm{C}$ group and $\mathrm{H}+\mathrm{CP}$ group were significantly decreased compared with the H group (Table III). The fecal TC, TG and
TBA levels were also significantly increased in the $\mathrm{H}$ group compared with the $\mathrm{N}$ group. In addition, compared with the $\mathrm{H}$ group, the TC, TG and TBA levels in the $\mathrm{H}+\mathrm{C}$ and $\mathrm{H}+\mathrm{CP}$ groups were significantly increased. Furthermore, the TC, TG and TBA levels in the $\mathrm{H}+\mathrm{CP}$ were significantly different from those in the $\mathrm{H}+\mathrm{C}$ group.

Effects of $C, P$ and $C P$ administration on the activity of serum LCAT and hepatic CYP7A1 in rats fed on a HFD. As shown in Table IV, compared with the $\mathrm{N}$ group, serum LCAT activity was markedly decreased in the $\mathrm{H}$ group. Administration of $\mathrm{CP}$ markedly increased the LCAT activity compared with the $\mathrm{H}$ or $\mathrm{H}+\mathrm{C}$ group. Compared with the $\mathrm{N}$ group, hepatic CYP7A1 activity was significantly increased in the $\mathrm{H}$ group. Administration of CP clearly increased the CYP7A1 activity compared with the $\mathrm{H}$ or $\mathrm{H}+\mathrm{C}$ group.

Effects of $C$ and $C P$ administration on the hepatic $m R N A$ levels of rats fed on a HFD. qPCR analysis was performed to measure the mRNA levels in the rat livers in each group (Fig. 1). Compared with the $\mathrm{H}$ and $\mathrm{H}+\mathrm{C}$ groups, administration of CP caused a marked increase in ApoAI, CYP7A1, LCAT and LDLR mRNA levels. However, no significant differences were observed between the groups for other mRNAs associated with cholesterol metabolism.

\section{Discussion}

In the present study, a significant increase in TC, TG and LDL-C levels, as well as a decrease in HDL-C levels in the H group was observed, indicating that HLP in SD rats was successfully induced via administration of a HFD. Administration of curcumin plus piperine resulted in a significant decrease in the serum TC, TG and LDL-C levels compared with the $\mathrm{H}$ and $\mathrm{H}+\mathrm{C}$ groups. Notably, the results from the present study demonstrated that curcumin did not significantly alter the HDL levels, which is consistent with the results from Kim et al (16); however, they are inconsistent with the results from Arafa et al (12). In addition, only curcumin plus piperine significantly increased the levels of ApoAI and HDL-C, as well as LCAT activity.

Notably, only curcumin plus piperine significantly increased the levels of HDL-C. Previous studies have demonstrated that HDL is synthesized through a complex pathway (31). HDL assembly initially involves the cell surface ABCA1 transporter-mediated transfer of phospholipids and cholesterol to the extracellular lipid-poor ApoAI. The plasma compartment of HDL particles is then remodeled by the esterification of cholesterol via the LCAT enzyme, the exchange between HDL and other lipoproteins and the putative transfer of cellular cholesterol to the growing particles by SR-B1, which is also an important receptor in cholesterol metabolism (32). In the present study, no significant differences in ABCA1 and SR-B1 mRNA levels were observed. Previous studies have demonstrated that the increase in LCAT activity and ApoAI levels may contribute to an increase in HDL-C concentrations (33-35). However, in the present study, a significant increase in the level of ApoAI and the activity of LCAT was observed in the $\mathrm{H}+\mathrm{CP}$ group. Therefore, to further explain the increase of serum HDL-C level in rats in the $\mathrm{H}+\mathrm{CP}$ group, the 
Table I. Growth parameters of rats fed on a HFD.

\begin{tabular}{lccccc}
\hline Parameter & $\mathrm{N}$ & $\mathrm{H}$ & $\mathrm{H}+\mathrm{C}$ & $\mathrm{H}+\mathrm{P}$ & $\mathrm{H}+\mathrm{CP}$ \\
\hline Initial body weight $(\mathrm{g})^{*}$ & $314.33 \pm 6.38$ & $307.15 \pm 5.25$ & $305.18 \pm 5.84$ & $303.98 \pm 8.12$ & $306.65 \pm 8.80$ \\
Final body weight $(\mathrm{g})^{* *}$ & $369.58 \pm 20.85$ & $358.83 \pm 19.69$ & $360.05 \pm 13.68$ & $365.93 \pm 11.04$ & $354.65 \pm 9.79$ \\
Body weight gain $(\mathrm{g})$ & $55.25 \pm 14.42$ & $51.68 \pm 15.23$ & $54.87 \pm 12.10$ & $54.37 \pm 12.18$ & $48.00 \pm 9.34$ \\
Food intake for 4 weeks $(\mathrm{g})$ & $393.77 \pm 12.22$ & $386.87 \pm 11.34$ & $374.25 \pm 13.77$ & $382.44 \pm 12.16$ & $361.32 \pm 12.09$ \\
Relative liver weight & $3.73 \pm 0.26$ & $3.65 \pm 0.38$ & $3.36 \pm 0.10$ & $3.44 \pm 0.18$ & $3.35 \pm 0.09$ \\
(g/100 g of body weight) & & & & & \\
\hline
\end{tabular}

The results are presented as the mean \pm standard deviation obtained from six rats in each group. *Body weight at the beginning of the 4-week oral administration of $\mathrm{C}, \mathrm{P}$ or $\mathrm{CP} .{ }^{* *}$ Body weight at the end of the 4-week oral administration of $\mathrm{C}, \mathrm{P}$ or CP. HFD, high-fat diet; N, normal control; H, HFD control; $\mathrm{H}+\mathrm{C}$, HFD plus curcumin; $\mathrm{H}+\mathrm{P}$, HFD plus piperine; $\mathrm{H}+\mathrm{CP}$, HFD plus curcumin plus piperine.

Table II. Effects of C, P and CP on the serum lipid levels of rats fed on a HFD.

\begin{tabular}{lcccrc}
\hline Parameter & $\mathrm{N}$ & $\mathrm{H}$ & $\mathrm{H}+\mathrm{C}$ & $\mathrm{H}+\mathrm{P}$ & $\mathrm{H}+\mathrm{CP}$ \\
\hline $\mathrm{TC}(\mathrm{mmol} / \mathrm{l})$ & $4.02 \pm 0.96$ & $7.16 \pm 1.59^{\mathrm{b}}$ & $5.18 \pm 1.47^{\mathrm{c}}$ & $6.63 \pm 1.89$ & $4.52 \pm 1.36^{\mathrm{d}, \mathrm{e}}$ \\
$\mathrm{TG}(\mathrm{mmol} / \mathrm{l})$ & $1.94 \pm 1.05$ & $4.28 \pm 1.17^{\mathrm{b}}$ & $3.07 \pm 1.30^{\mathrm{c}}$ & $4.07 \pm 1.16$ & $1.96 \pm 1.33^{\mathrm{d}, \mathrm{e}}$ \\
HDL-C (mmol/l) & $2.85 \pm 0.58$ & $1.70 \pm 0.16^{\mathrm{a}}$ & $1.84 \pm 0.51$ & $1.61 \pm 0.24$ & $2.88 \pm 0.46^{\mathrm{d}, \mathrm{e}}$ \\
LDL-C (mmol/l) & $1.16 \pm 0.66$ & $5.34 \pm 0.52^{\mathrm{b}}$ & $3.30 \pm 1.18^{\mathrm{c}}$ & $5.01 \pm 0.43$ & $1.64 \pm 0.77^{\mathrm{d}, \mathrm{e}}$ \\
ApoAI (g/l) & $0.063 \pm 0.006$ & $0.018 \pm 0.006^{\mathrm{b}}$ & $0.024 \pm 0.010$ & $0.021 \pm 0.009$ & $0.064 \pm 0.011^{\mathrm{d}, \mathrm{e}}$ \\
ApoB (g/l) & $0.075 \pm 0.017$ & $0.112 \pm 0.010^{\mathrm{a}}$ & $0.109 \pm 0.011$ & $0.114 \pm 0.019$ & $0.107 \pm 0.012$
\end{tabular}

The results are presented as the mean \pm standard deviation obtained from six rats in each group. ${ }^{\mathrm{a}} \mathrm{P}<0.05,{ }^{\mathrm{b}} \mathrm{P}<0.01 \mathrm{vs} . \mathrm{N}$ group; ${ }^{\mathrm{c}} \mathrm{P}<0.05,{ }^{\mathrm{d}} \mathrm{P}<0.01$ vs. H group; ${ }^{\mathrm{e}} \mathrm{P}<0.05$, vs. H + C group. HFD, high-fat diet; TC, total cholesterol; TG, triglyceride; HDL-C, high-density lipoprotein cholesterol; LDL-C, low-density lipoprotein cholesterol; Apo, apolipoprotein; N, normal control; H, HFD control; H + C, HFD plus curcumin; H + P, HFD plus piperine; $\mathrm{H}+\mathrm{CP}, \mathrm{HFD}$ plus curcumin plus piperine.

Table III. Effect of C, P and CP administration on hepatic and fecal lipid levels of rats fed on a HFD.

\begin{tabular}{lrrrrr}
\hline Parameter & N & H & H C & H + P & H + CP \\
\hline TC $(\mu \mathrm{mol} / \mathrm{g} \text { liver })^{*}$ & $9.97 \pm 3.12$ & $34.76 \pm 4.31^{\mathrm{b}}$ & $20.38 \pm 2.86^{\mathrm{c}}$ & $29.91 \pm 3.17$ & $12.52 \pm 2.27^{\mathrm{de}}$ \\
$\mathrm{TG}(\mu \mathrm{mol} / \mathrm{g} \text { liver })^{*}$ & $17.26 \pm 3.78$ & $40.35 \pm 4.84^{\mathrm{b}}$ & $27.90 \pm 3.06^{\mathrm{c}}$ & $36.46 \pm 4.38$ & $22.56 \pm 3.44^{\mathrm{de}}$ \\
$\mathrm{TC}(\mu \mathrm{mol} / \mathrm{g} \text { of feces/day })^{\#}$ & $5.69 \pm 1.47$ & $11.10 \pm 2.29^{\mathrm{b}}$ & $14.77 \pm 2.51^{\mathrm{c}}$ & $12.05 \pm 2.40$ & $17.33 \pm 3.16^{\mathrm{de}}$ \\
TG $(\mu \mathrm{mol} / \mathrm{g} \text { of feces/day })^{\#}$ & $1.71 \pm 0.36$ & $3.84 \pm 2.25^{\mathrm{b}}$ & $6.16 \pm 2.37^{\mathrm{c}}$ & $4.92 \pm 2.12$ & $7.05 \pm 2.40^{\mathrm{de}}$ \\
TBA $(\mu \mathrm{mol} / \mathrm{g} \text { of feces/day })^{\#}$ & $169.21 \pm 30.8$ & $218.10 \pm 16.65^{\mathrm{a}}$ & $241.82 \pm 20.50^{\mathrm{c}}$ & $225.63 \pm 18.47$ & $266.44 \pm 29.43^{\mathrm{de}}$ \\
\hline
\end{tabular}

The results are presented as the mean \pm standard deviation from six rats in each group. ${ }^{\text {H}}$ Hepatic lipids and ${ }^{\#} \mathrm{Fecal}$ lipids. ${ }^{\mathrm{a}} \mathrm{P}<0.05$, ${ }^{\mathrm{b}} \mathrm{P}<0.01$, vs $\mathrm{N}$ group; ${ }^{\mathrm{C}} \mathrm{P}<0.05,{ }^{\mathrm{d}} \mathrm{P}<0.01$ vs. $\mathrm{H}$ group; ${ }^{\mathrm{e}} \mathrm{P}<0.05,{ }^{\mathrm{P}} \mathrm{P}<0.01 \mathrm{vs} . \mathrm{H}+\mathrm{C}$ group. HFD, high-fat diet; TC, total cholesterol; TG, triglyceride; TBA, total bile acid; $\mathrm{N}$, normal control; $\mathrm{H}$, HFD control; $\mathrm{H}+\mathrm{C}$, HFD plus curcumin; $\mathrm{H}+\mathrm{P}$, HFD plus piperine; $\mathrm{H}+\mathrm{CP}$, $\mathrm{HFD}$ plus curcumin plus piperine.

expression of ApoAI and LCAT mRNA was analyzed. It was found that the mRNA levels of LCAT and ApoAI significantly increased following administration of curcumin and piperine, suggesting a co-ordinated regulatory mechanism of ApoAI and LCAT mRNA expression. This suggests that the higher level of HDL-C in rats in the $\mathrm{H}+\mathrm{CP}$ group may be due to alterations in the mRNA expression of ApoAI and LCAT. Therefore, this indicates that curcumin plus piperine increases cholesterol efflux to HDL particles by elevating the ApoAI and LCAT mRNA levels, resulting in a significant increase in serum HDL-C levels.

Cholesterol metabolism is primarily conducted in the liver. The conversion of cholesterol to bile acids in the liver is an important pathway for the elimination of cholesterol from the body (36), which accounts for $\sim 50 \%$ of daily cholesterol excretion (37). CYP7A1 is a liver-specific enzyme that catalyzes the rate-limiting step in the biosynthesis of bile acid from cholesterol (38). An increase in hepatic CYP7A1 gene expres- 
Table IV. Effect of C, P and CP administration on the activity of CYP7A1 and LCAT in rats fed on a HFD.

\begin{tabular}{lccccr}
\hline Parameter & $\mathrm{N}$ & $\mathrm{H}$ & $\mathrm{H}+\mathrm{C}$ & $\mathrm{H}+\mathrm{P}$ & $\mathrm{H}+\mathrm{CP}$ \\
\hline LCAT $(\mathrm{nmol} / \mathrm{h} / \mathrm{ml})$ & $16.3 \pm 2.01$ & $9.68 \pm 1.37^{\mathrm{b}}$ & $10.29 \pm 1.17$ & $9.70 \pm 0.87$ & $13.95 \pm 1.00^{\text {de }}$ \\
CYP7A1 (nmol/h/mg protein) & $1.12 \pm 0.39$ & $1.77 \pm 0.46^{\mathrm{a}}$ & $2.23 \pm 0.75^{\mathrm{c}}$ & $1.75 \pm 0.48$ & $3.04 \pm 0.61^{\text {de }}$ \\
\hline
\end{tabular}

The results are presented as the mean \pm standard deviation obtained from six rats in each group. ${ }^{\mathrm{a}} \mathrm{P}<0.05,{ }^{\mathrm{b}} \mathrm{P}<0.01, \mathrm{vs}$. $\mathrm{N}$ group; ${ }^{\mathrm{c}} \mathrm{P}<0.05$, ${ }^{\mathrm{d}} \mathrm{P}<0.01$, vs. $\mathrm{H}$ group; ${ }^{\mathrm{P}}<0.05,{ }^{\mathrm{f}} \mathrm{P}<0.01$, vs. $\mathrm{H}+\mathrm{C}$ group. LCAT, lecithin cholesterol acyltransferase; CYP7A1, cholesterol 7 $\alpha$-hydroxylase; HFD, high-fat diet; N, normal control; H, HFD control; H + C, HFD plus curcumin; H + P, HFD plus piperine; H + CP, HFD plus curcumin plus piperine.

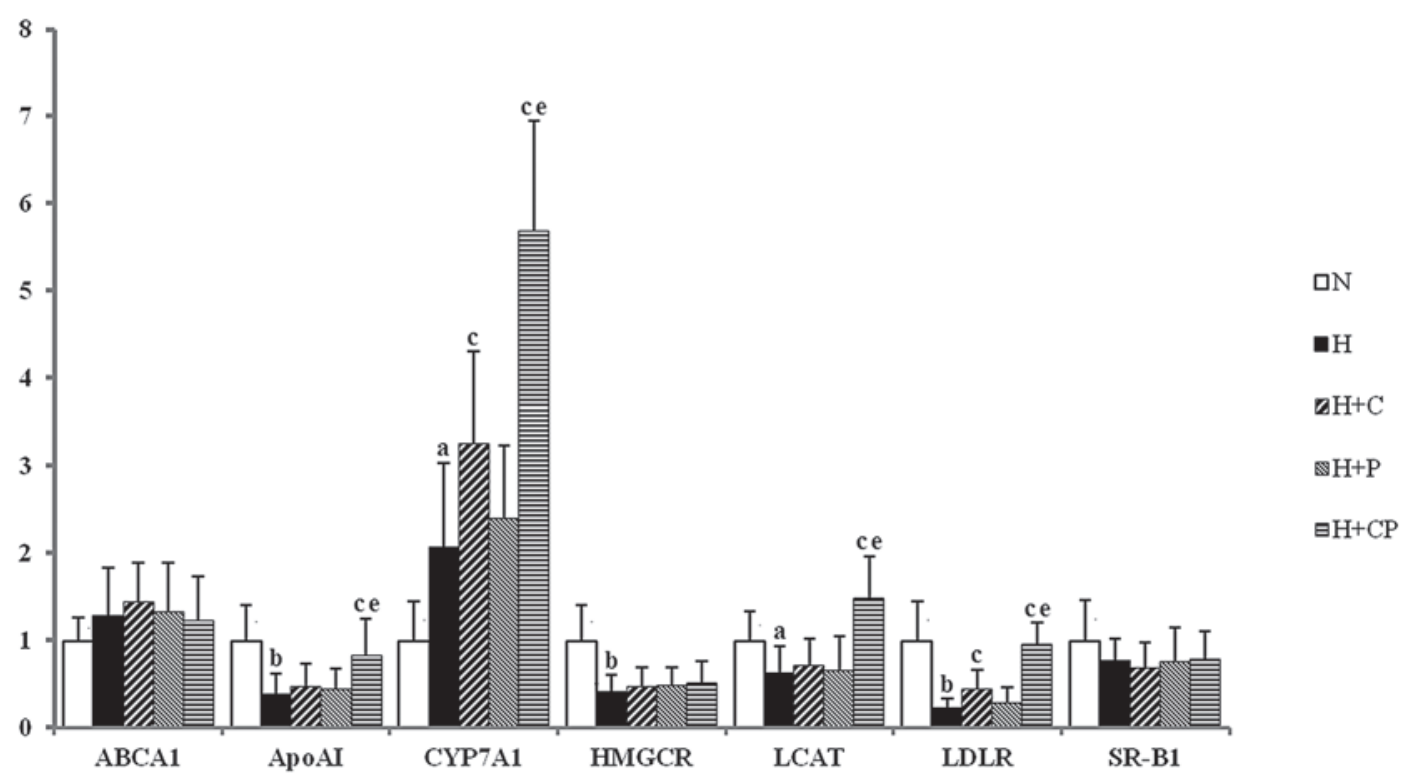

Figure 1. Analysis of hepatic mRNA levels using quantitative polymerase chain reaction of rats in each group. The relative mRNA levels are presented as the mean \pm standard deviation obtained from six rats in each group. ${ }^{\mathrm{a}} \mathrm{P}<0.05,{ }^{\mathrm{b}} \mathrm{P}<0.01$, vs. $\mathrm{N}$ group; ${ }^{\mathrm{C}} \mathrm{P}<0.05$, vs. $\mathrm{H}$ group; ${ }^{\mathrm{P}}<0.05$, vs. $\mathrm{H}+\mathrm{C}$ group. $\mathrm{N}$, normal control; $\mathrm{H}$, high-fat diet control; $\mathrm{H}+\mathrm{C}$, high-fat diet plus curcumin; $\mathrm{H}+\mathrm{P}$, high-fat diet plus piperine; $\mathrm{H}+\mathrm{CP}$, high-fat diet plus curcumin plus piperine; $\mathrm{ABCA}$, ATP-binding cassette transporter A1; ApoA1, apolipoprotein AI; CYP7A1, cholesterol 7 $\alpha$-hydroxylase; HMGCR, HMG-CoA reductase; LCAT, lecithin cholesterol acyltransferase; LDLR, low-density lipoprotein receptor; SR-B1, scavenger receptor B1.

sion may contribute to the enhancement of CYP7A1 activity and therefore increase the fecal bile acid levels. This may lead to an increase in the quantity of cholesterol that is excreted out of the body and thus lead to a decrease in serum cholesterol levels. In the present study, the expression level of CYP7A1 was found to be markedly upregulated by high plasma cholesterol in the $\mathrm{H}$ group, suggesting that the synthesis of bile acid is positively associated with plasma cholesterol levels (39). Increased CYP7A1 mRNA levels were also observed in rats treated with curcumin, which is in accordance with the results obtained by Kim et al (16). Furthermore, the present study found that curcumin plus piperine increased CYP7A1 activity and gene expression to a greater extent than curcumin alone. This demonstrated that curcumin plus piperine increased the rate of bile acid production, which is the precursor molecule for cholesterol synthesis and, therefore, curcumin and piperine induce a more efficient removal of excessive cholesterol from the blood. However, a certain amount of cholesterol may also be transformed into fecal cholesterol by microbes in the intestine and excreted through the feces (26). The results from the present study demonstrated that fecal TC and TG levels were greater in rats administrated with curcumin plus piperine compared with rats in the other groups. These results are consistent with the previous studies that found a curcumin-mediated increase in fecal excretion of cholesterol $(16,40)$.

The mRNA levels of genes associated with cholesterol synthesis were measured in the present study. HMGCR is a rate-limiting enzyme in cholesterol synthesis $(14,41)$. The present study demonstrated that the mRNA expression of HMGCR in the $\mathrm{H}$ group was inhibited due to feedback inhibition induced by an increase in exogenous cholesterol. In addition, no significant differences were observed among the three groups, including the $\mathrm{H}, \mathrm{H}+\mathrm{C}$ and $\mathrm{H}+\mathrm{CP}$ groups, suggesting neither $\mathrm{C}$ nor $\mathrm{CP}$ affected the synthesis of cholesterol. LDLR is an important receptor that mediates the clearance of LDL-C in the blood. It has previously been demonstrated that curcumin treatment upregulated LDLR mRNA levels in human hepatoma HepG2 cells $(42,43)$ and $\mathrm{SD}$ rats (16). The present study revealed that curcumin plus piperine had a more significant effect on LDLR mRNA expression levels than curcumin alone, leading to a marked decrease in LDL-C levels. 
In combination, the results from the present study demonstrated that piperine was able to enhance the hypocholesterolemic effect of curcumin via modulating the expression of a number of genes involved in cholesterol metabolism. In the presence of piperine, curcumin was found to increase the mRNA expression levels of ApoAI, CYP7A1, LCAT and LDLR, leading to an increase in the transformation of cholesterol to bile acid, an increase in HDL-C levels and a reduction of LDL-C levels. Therefore, this suggests that redundant TC in the blood may be removed by HDL and transferred to the feces. It has previously been demonstrated that the combination of piperine and curcumin was able to increase bioavailability of curcumin $(17,20)$. The present study demonstrated that administration of piperine alone $(5 \mathrm{mg} / \mathrm{kg} / \mathrm{day})$ had no significant hypocholesterolemic effect; however, administration of piperine plus curcumin markedly increased the hypocholesterolemic effect, via upregulation of the activity and gene expression levels of ApoAI, CYP7A1, LCAT and LDLR. This suggests that the enhanced ability of curcumin plus piperine compared with curcumin alone in lowering serum cholesterol level is due to an increase in the bioavailability of curcumin.

In conclusion, co-administration of curcumin plus piperine was found to decrease the serum and liver levels of TC, TG and LDL-C, as well as increase the fecal levels of TC, TG and TBA to a greater extent compared with curcumin alone. In addition, curcumin plus piperine markedly increased the levels of HDL-C. Furthermore, compared with administration of curcumin alone, administration of curcumin plus piperine resulted in a more significant upregulation of the activities and gene expression levels of ApoAI, LCAT, CYP7A1 and LDLR. Therefore, the results from the present study demonstrate that co-administration of curcumin plus piperine is better than administration of curcumin alone against HLP, providing a promising combination for the treatment of HLP.

\section{Acknowledgements}

This study was supported by the Natural Science Foundation of Guangdong Province, China (grant no. S2011010005928 and S2013010012360), the Administration of Traditional Medicine of Guangdong Province, China (grant no. 2010268) and the Guangzhou Science and Technology and Information Bureau (grant no. 2010Y1-C761).

\section{References}

1. Assmann G, Cullen P, Jossa F, Lewis B and Mancini M: Coronary heart disease: reducing the risk: the scientific background to primary and secondary prevention of coronary heart disease. A worldwide view. International Task force for the Prevention of Coronary Heart disease. Arterioscler Thromb Vasc Biol 19: 1819-1824, 1999.

2. Asai A and Miyazawa T: Dietary curcuminoids prevent high-fat diet-induced lipid accumulation in rat liver and epididymal adipose tissue. J Nutr 131: 2932-2935, 2001.

3. Aggarwal BB, Kumar A and Bharti AC: Anticancer potential of curcumin: preclinical and clinical studies. Anticancer Res 23: 363-398, 2003

4. Holt PR, Katz S and Kirshoff R: Curcumin therapy in inflammatory bowel disease: a pilot study. Dig Dis Sci 50: 2191-2193 2005.

5. Shehzad A, Ha T, Subhan F and Lee YS: New mechanisms and the anti-inflammatory role of curcumin in obesity and obesity-related metabolic diseases. Eur J Nutr 50: 151-161, 2011.
6. Killian PH, Kronski E, Michalik KM, et al: Curcumin inhibits prostate cancer metastasis in vivo by targeting the inflammatory cytokines CXCL1 and -2. Carcinogenesis 33: 2507-2519, 2012.

7. Sadzuka Y, Nagamine M, Toyooka T, Ibuki Y and Sonobe T: Beneficial effects of curcumin on antitumor activity and adverse reactions of doxorubicin. Int J Pharm 432: 42-49, 2012.

8. Sahin K, Orhan C, Tuzcu Z, Tuzcu M and Sahin N: Curcumin ameloriates heat stress via inhibition of oxidative stress and modulation of Nrf2/HO-1 pathway in quail. Food Chem Toxicol 50: 4035-4041, 2012

9. Meng B, Li J and Cao H: Antioxidant and antiinflammatory activities of curcumin on diabetes mellitus and its complications. Curr Pharm Des 19: 2101-2113, 2013.

10. Shehzad A, Rehman G and Lee YS: Curcumin in inflammatory diseases. Biofactors 39: 69-77, 2013.

11. Tokaç M, Taner G, Aydın S, et al: Protective effects of curcumin against oxidative stress parameters and DNA damage in the livers and kidneys of rats with biliary obstruction. Food Chem Toxicol 61: 28-35, 2013.

12. Arafa HM: Curcumin attenuates diet-induced hypercholesterolemia in rats. Med Sci Monit 11: BR228-BR234, 2005

13. Manjunatha $\mathrm{H}$ and Srinivasan K: Hypolipidemic and antioxidant effects of dietary curcumin and capsaicin in induced hypercholesterolemic rats. Lipids 42: 1133-1142, 2007.

14. Jang EM, Choi MS, Jung UJ, et al: Beneficial effects of curcumin on hyperlipidemia and insulin resistance in high-fat-fed hamsters. Metabolism 57: 1576-1583, 2008.

15. Kapoor P, Ansari MN and Bhandari U: Modulatory effect of curcumin on methionine-induced hyperlipidemia and hyperhomocysteinemia in albino rats. Indian J Exp Biol 46: 534-540, 2008.

16. Kim M and Kim Y: Hypocholesterolemic effects of curcumin via up-regulation of cholesterol 7a-hydroxylase in rats fed a high fat diet. Nutr Res Pract 4: 191-195, 2010.

17. Anand P, Kunnumakkara AB, Newman RA and Aggarwal BB: Bioavailability of curcumin: problems and promises. Mol Pharm 4: 807-818, 2007.

18. Srinivasan K: Black pepper and its pungent principle-piperine: a review of diverse physiological effects. Crit Rev Food Sci Nutr 47: 735-748, 2007.

19. Shoba G, Joy D, Joseph T, Majeed M, Rajendran R and Srinivas PS: Influence of piperine on the pharmacokinetics of curcumin in animals and human volunteers. Planta Med 64: 353-356, 1998

20. Suresh D and Srinivasan K: Tissue distribution \& elimination of capsaicin, piperine \& curcumin following oral intake in rats. Indian J Med Res 131: 682-691, 2010.

21. Bhutani MK, Bishnoi M and Kulkarni SK: Anti-depressant like effect of curcumin and its combination with piperine in unpredictable chronic stress-induced behavioral, biochemical and neurochemical changes. Pharmacol Biochem Behav 92: 39-43, 2009.

22. Rinwa $\mathrm{P}$ and Kumar A: Piperine potentiates the protective effects of curcumin against chronic unpredictable stress-induced cognitive impairment and oxidative damage in mice. Brain Res 1488: 38-50, 2012

23. Sehgal A, Kumar M, Jain M and Dhawan DK: Piperine as an adjuvant increases the efficacy of curcumin in mitigating benzo(a)pyrene toxicity. Hum Exp Toxicol 31: 473-482, 2012.

24. Kaur G and C M: Amelioration of obesity, glucose intolerance, and oxidative stress in high-fat diet and low-dose streptozotocin-induced diabetic rats by combination consisting of 'curcumin with piperine and quercetin'. ISRN Pharmacol 2012: 957283, 2012.

25. Feldmann D, Fenech C and Cuer JF: Evaluation of a sample-preparation procedure for bile acids in serum and bile. Clin Chem 29: 1694, 1983.

26. Gong J, Peng C, Chen T, Gao B and Zhou H: Effects of theabrownin from pu-erh tea on the metabolism of serum lipids in rats: mechanism of action. J Food Sci 75: H182-H189, 2010.

27. Kleinsek DA, Ranganathan S and Porter JW: Purification of 3-hydroxy-3-methylglutaryl-coenzyme A reductase from rat liver. Proc Natl Acad Sci USA 74: 1431-1435, 1977.

28. Yamazaki H, Inoue K, Turvy CG, Guengerich FP and Shimada T: Effects of freezing, thawing, and storage of human liver samples on the microsomal contents and activities of cytochrome P450 enzymes. Drug Metab Dispos 25: 168-174, 1997.

29. Honda A, Salen G, Matsuzaki Y, et al: Differences in hepatic levels of intermediates in bile acid biosynthesis between Cyp27(-/-) mice and CTX. J Lipid Res 42: 291-300, 2001. 
30. Hylemon PB, Studer EJ,Pandak WM,Heuman DM, Vlahcevic ZR and Chiang JY: Simultaneous measurement of cholesterol 7 alpha-hydroxylase activity by reverse-phase high-performance liquid chromatography using both endogenous and exogenous [4-14C]cholesterol as substrate. Anal Biochem 182: 212-216, 1989.

31. Zannis VI, Chroni A, Kypreos KE, et al: Probing the pathways of chylomicron and HDL metabolism using adenovirus-mediated gene transfer. Curr Opin Lipidol 15: 151-166, 2004.

32. Krieger M: Scavenger receptor class B type I is a multiligand HDL receptor that influences diverse physiologic systems. J Clin Invest 108: 793-797, 2001.

33. Hoeg JM, Santamarina-Fojo S, Bérard AM, et al: Overexpression of lecithin:cholesterol acyltransferase in transgenic rabbits prevents diet-induced atherosclerosis. Proc Natl Acad Sci USA 93: 11448-11453, 1996.

34. Brousseau ME, Santamarina-Fojo S, Vaisman BL, et al: Overexpression of human lecithin:cholesterol acyltransferase in cholesterol-fed rabbits: LDL metabolism and HDL metabolism are affected in a gene dose-dependent manner. J Lipid Res 38: 2537-2547, 1997.

35. Aizawa $\mathrm{K}$ and Inakuma $\mathrm{T}$ : Dietary capsanthin, the main carotenoid in paprika (Capsicum annuum), alters plasma high-density lipoprotein-cholesterol levels and hepatic gene expression in rats. Br J Nutr 102: 1760-1766, 2009.
36. Zhang Z, Wang H, Jiao R, et al: Choosing hamsters but not rats as a model for studying plasma cholesterol-lowering activity of functional foods. Mol Nut Food Res 53: 921-930, 2009.

37. Kuwabara T, Han KH, Hashimoto N, et al: Tartary buckwheat sprout powder lowers plasma cholesterol level in rats. J Nutr Scie Vitaminol (Tokyo) 53: 501-507, 2007.

38. Russell DW and Setchell KD: Bile acid biosynthesis. Biochemistry 31: 4737-4749, 1992

39. Yiu WF, Kwan PL, Wong CY, et al: Attenuation of fatty liver and prevention of hypercholesterolemia by extract of Curcuma longa through regulating the expression of CYP7A1, LDL-receptor, HO-1, and HMG-CoA reductase. J Food Sci 76: H80-H89, 2011.

40. Rao DS, Sekhara NC, Satyanarayana MN and Srinivasan M: Effect of curcumin on serum and liver cholesterol levels in the rat. J Nutr 100: 1307-1315, 1970.

41. Goldstein JL and Brown MS: Regulation of the mevalonate pathway. Nature 343: 425-430, 1990.

42. Peschel D, Koerting R and Nass N: Curcumin induces changes in expression of genes involved in cholesterol homeostasis. J Nutr Biochem 18: 113-119, 2007.

43. Dou X, Fan C, Wo L, Yan J, Qian Y and Wo X: Curcumin up-regulates LDL receptor expression via the sterol regulatory element pathway in HepG2 cells. Planta medica 74: 1374-1379, 2008. 